\title{
Transanal approach for intersphincteric resection of rectal cancer in a patient with a huge prostatic hypertrophy
}

\author{
Yoshiyuki Kiyasu $^{1} \cdot$ Kenji Kawada $^{1} \cdot$ Kyoichi Hashimoto $^{1} \cdot$ Ryo Takahashi $^{1}$. \\ Koya Hida $^{1}$ - Yoshiharu Sakai ${ }^{1}$
}

Received: 20 October 2016/Accepted: 15 November 2016/Published online: 24 November 2016

(c) The Author(s) 2016. This article is published with open access at Springerlink.com

\begin{abstract}
The gold standard of surgical technique for rectal cancer is total mesorectal excision (TME). Laparoscopic TME has been proven to provide surgical safety and oncological outcomes equivalent to open TME. However, dissection of the lower rectum has some inherent difficulties related to a narrow pelvic space. The challenge of TME in the lower rectum was confirmed by the Colorectal Cancer Laparoscopic or Open Resection (COLOR) II trial showing a $9 \%$ positive circumferential margin (CRM) rate in laparoscopic TME and a $22 \%$ positive CRM rate in open TME. Recently, transanal TME has attracted intense attention as a promising alternative to laparoscopic TME. In this video article, we show the performance of a transanal approach for intersphincteric resection (ISR) of rectal cancer in a patient with a huge prostatic hypertrophy.
\end{abstract}

Keywords Transanal approach · Total mesorectal excision - Intersphincteric resection · Rectal cancer . Prostatic hypertrophy

\section{Introduction}

The gold standard of surgical technique for rectal cancer is total mesorectal excision (TME) [1]. Laparoscopic TME has been proven to provide surgical safety and

Electronic supplementary material The online version of this article (doi:10.1007/s13691-016-0272-8) contains supplementary material, which is available to authorized users.

Kenji Kawada

kkawada@kuhp.kyoto-u.ac.jp

1 Department of Surgery, Graduate School of Medicine, Kyoto University, 54 Shogoin- Kawara-cho, Sakyo-ku, Kyoto 606-8507, Japan oncological outcomes equivalent to open TME [2, 3]. However, dissection of the lower rectum has some inherent difficulties related to a narrow pelvic space. The challenge of TME in the lower rectum was confirmed by the Colorectal Cancer Laparoscopic or Open Resection (COLOR) II trial showing a 9\% positive circumferential margin (CRM) rate in laparoscopic TME and a $22 \%$ positive CRM rate in open TME [2]. Recently, transanal TME has attracted intense attention as a promising alternative to laparoscopic TME [4-8]. In this video article, we show the performance of a transanal approach for intersphincteric resection (ISR) of rectal cancer in a patient with a huge prostatic hypertrophy.

\section{Case presentation}

An 80-year-old man was admitted to our hospital for the treatment of a rectal tumor found incidentally by rectal examination. The tumor, about $3 \mathrm{~cm}$ in diameter, was located on the right side of the lower rectum $3 \mathrm{~cm}$ above the anal verge. The pathological analysis of the biopsy sample revealed that the tumor was a moderately differentiated adenocarcinoma. Abdominal computed tomography (CT) and magnetic resonance imaging (MRI) indicated that the rectal cancer invaded into the muscularis propria without distant metastases and that lateral pelvic lymph node (LPLN) was not enlarged with a maximum long-axis diameter $<3 \mathrm{~mm}$. The most important problem was that the patient had a huge benign prostatic hypertrophy, the size of which was $85 \times 80 \times 70 \mathrm{~mm}$ (Fig. 1a-c). To achieve complete TME with negative CRM, a hybrid transabdominal-transanal approach for ISR was conducted. 

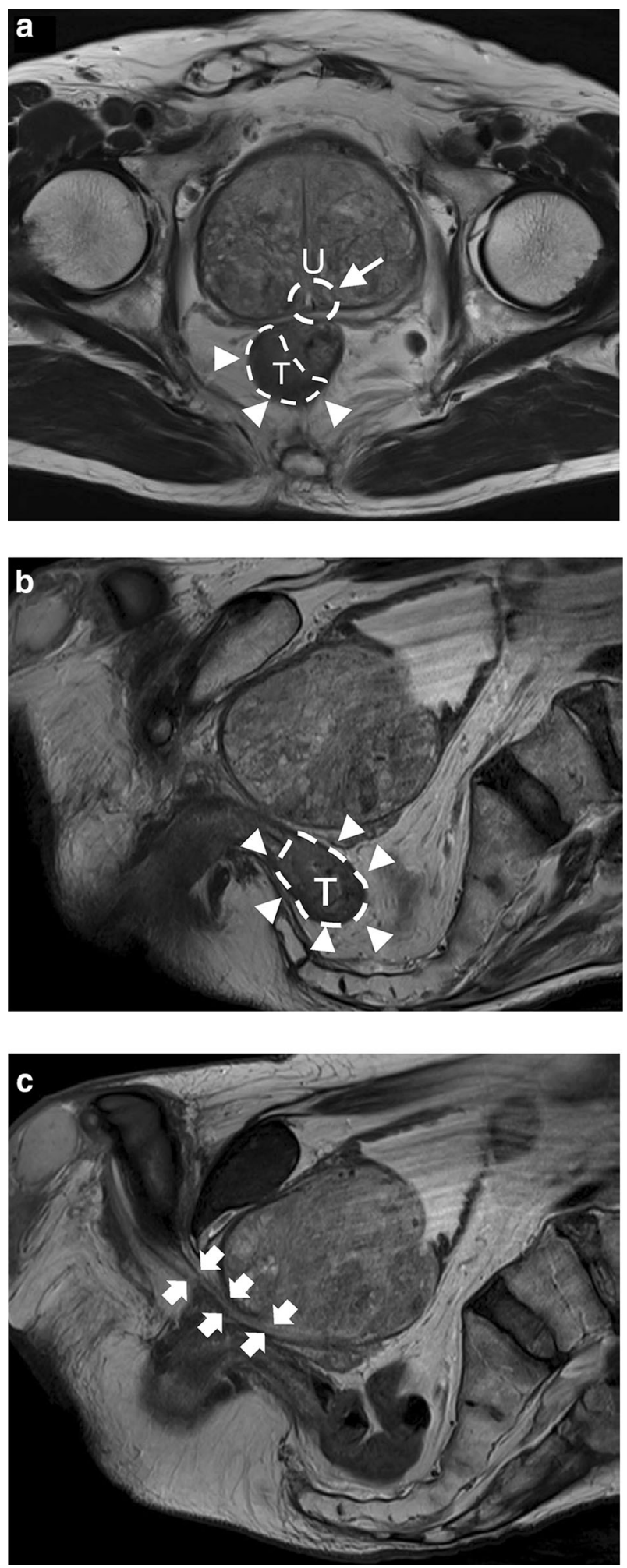

Fig. 1 T2-weighted image of MRI. a Axial section. The urethra (white arrow) was just above the tumor (white arrowhead). $T$ tumor, $U$ urethra. b Midline sagittal section. The tumor (white arrowhead) was located $3 \mathrm{~cm}$ above the anal verge. $T$ tumor. c Sub midline sagittal section. The urethra (white arrow) was deviated by a huge prostate

\section{Technique}

First, vascular division and mobilization of the left colon were performed laparoscopically. The transabdominal approach was continued until the anterior dissection of the rectum became difficult due to a huge prostatic hypertrophy. Next, the circumferential rectal incision and subsequent intersphincteric dissection were performed under direct vision to enable attachment of a single port device (GelPoint Mini; Applied Medical). After closure of the anal orifice, the GelPoint Mini was placed to start the transanal approach. Posterior side of the rectum was first dissected until the transanal approach was connected to the dissection layer made by the transabdominal approach. The dissection procedure was extended to the lateral side. Bilateral pelvic splanchnic nerves were identified at the 5 and 7 o'clock positions. At the anterior side, the proper dissection layer cannot be easily identified because of the perineal body and the enlarged prostate. Once the dissection plane between the rectum and the prostate could be identified, it was relatively easy to continue along the same plane. The assistance provided by the laparoscopic approach was useful to determine the appropriate dissection line in the transanal approach.

\section{Result}

The total operative time was $491 \mathrm{~min}$, and the blood loss was $116 \mathrm{ml}$. Macroscopic findings of the resected specimen showed a solid tumor, $25 \times 25 \mathrm{~mm}$ in size, and the distal margin was $40 \mathrm{~mm}$ (Fig. 2a). On histopathological analysis, the tumor staging was Stage I (pT2N0M0 according to the 7th edition UICC) and the CRM was negative (the free distance of the CRM was $3000 \mu \mathrm{m}$ ) (Fig. 2b). LPLN dissection was not performed, because the indication for LPLN dissection in our institution was defined as LPLN with a short-axis diameter $\geq 5 \mathrm{~mm}$.

\section{Discussion}

Transanal TME is not well-established technically, but it has potential advantages, including superior visualization, facilitation of TME of the lower rectum, and shorter surgical time and less morbidity [4-8]. The factors that can make transanal TME a preferred approach are (1) male sex, (2) very low location (less than $12 \mathrm{~cm}$ from the anal verge), (3) narrow and deep pelvis, (4) visceral obesity (BMI $>30 \mathrm{~kg} / \mathrm{m}^{2}$ ), (5) prostatic hypertrophy, (6) large tumor ( $>4 \mathrm{~cm}$ in diameter), (7) distorted tissue planes due to preoperative radiotherapy, and (8) impalpable, low 

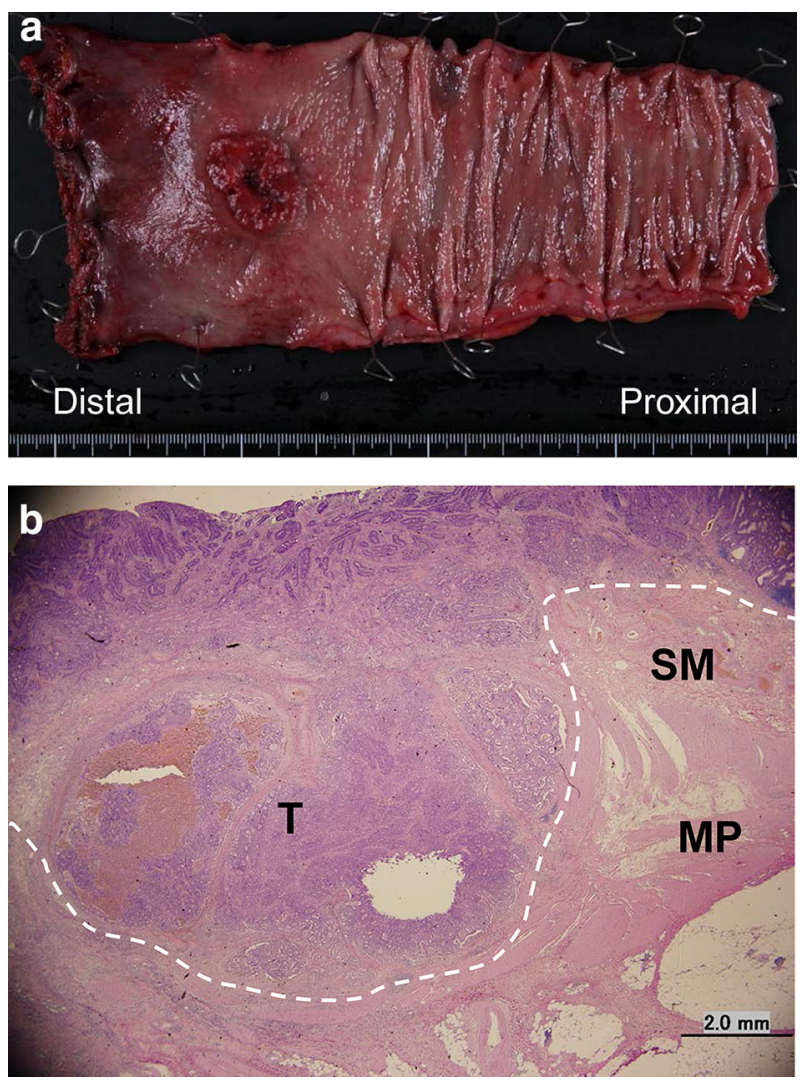

Fig. 2 Macroscopic and histolopathological findings of the specimen. a Macroscopic finding. The size of the tumor was $25 \times 25 \mathrm{~mm}$ in size. The distal margin was $40 \mathrm{~mm}$. b Histolopathological analysis revealed that the tumor was a moderately differentiated adenocarcinoma (Stage I: T2 (MP), N0 (0/9), and M0 according to the 7th edition UICC). The free distance of CRM was $3000 \mu \mathrm{m}$. The dotted line the horizontal margin of the tumor, $T$ tumor, $S M$ submucosa, $M P$ muscular propria

primary tumor [6]. The hybrid approach composed of both transanal and conventional laparoscopic TME can be an especially appropriate choice for difficult cases, such as a huge tumor occupied within a very narrow pelvic space. In this case, extremely huge prostatic hypertrophy made it difficult to determine the appropriate dissection line of TME, especially on the anterior side of the rectum. Transanal TME with the assistance of the conventional laparoscopic approach is very useful to identify the correct TME plane for rectal cancer patients with prostatic hypertrophy.

\section{Compliance with ethical standards}

Conflict of interest The authors declare that they have no conflict of interests.
Research involving human participants and/or animals For this type of study, formal consent is not required.

Informed consent Written informed consent was obtained from the patient for publication of this Case report and any accompanying images. A copy of the written consent is available for review by the Editor-in-Chief of the journal.

Open Access This article is distributed under the terms of the Creative Commons Attribution 4.0 International License (http://crea tivecommons.org/licenses/by/4.0/), which permits unrestricted use, distribution, and reproduction in any medium, provided you give appropriate credit to the original author(s) and the source, provide a link to the Creative Commons license, and indicate if changes were made.

\section{References}

1. Heald RJ, Ryall RD (1986) Recurrence and survival after total mesorectal excision for rectal cancer. Lancet 1:1479-1482

2. Bonjer HJ, Deijen CL, Abis GA, Cuesta MA, van der Pas MH, de Lange-de Klerk ES, Lacy AM, Bemelman WA, Andersson J, Angenete E, Rosenberg J, Fuerst A, Haglind E, COLOR II Study Group (2015) A randomized trial of laparoscopic versus open surgery for rectal cancer. N Engl J Med 372:1324-1332

3. Jeong SY, Park JW, Nam BH, Kim S, Kang SB, Lim SB, Choi HS, Kim DW, Chang HJ, Kim DY, Jung KH, Kim TY, Kang GH, Chie EK, Kim SY, Sohn DK, Kim DH, Kim JS, Lee HS, Kim JH, Oh JH (2014) Open versus laparoscopic surgery for mid-rectal or lowrectal cancer after neoadjuvant chemoradiotherapy (COREAN trial): survival outcomes of an open-label, non-inferiority, randomised controlled trial. Lancet Oncol 15:767-774

4. Fernández-Hevia M, Delgado S, Castells A, Tasende M, Momblan D, Díaz del Gobbo G, DeLacy B, Balust J, Lacy AM (2015) Transanal total mesorectal excision in rectal cancer: short-term outcomes in comparison with laparoscopic surgery. Ann Surg 261:221-227

5. Lacy AM, Tasende MM, Delgado S, Fernandez-Hevia M, Jimenez M, De Lacy B, Castells A, Bravo R, Wexner SD, Heald RJ (2015) Transanal total mesorectal excision for rectal cancer: outcomes after 140 patients. J Am Coll Surg 221:415-423

6. Motson RW, Whiteford MH, Hompes R, Albert M, Miles WF, Expert Group (2016) Current status of trans-anal total mesorectal excision (TaTME) following the Second International Consensus Conference. Colorectal Dis 8:13-18

7. Hasegawa S, Hida K, Kawada K, Sakai Y (2016) Transanal total mesorectal excision for rectal cancer: a video demonstration of rectal dissection. Dis Colon Rectum 59:157

8. Kawada K, Hasegawa S, Hida K, Sakai Y (2016) Advantages of the transanal approach for intersphincteric resection-a video vignette. Colorectal Dis 18:820 